(EDITORIAL)

\title{
Editorial introduction to first issue of GSC Biological and Pharmaceutical Sciences
}

\author{
Dr. Chaudhari G. M. * \\ Department of Biochemistry, Moolji Jaitha College, KCE Society, Jalgaon, (MS) India.
}

https://doi.org/10.30574/gscbps.2017.1.1.0001

\section{Dear GSCBPS Readers,}

Welcome to our inaugural issue of GSC Biological and Pharmaceutical Sciences (GSCBPS)!!!

On behalf of the Editorial Board, it is great pride and sincere privilege that I am writing this message to present the first issue of the GSC Biological and Pharmaceutical Sciences published by GSC online Press.

The GSC Biological and Pharmaceutical Sciences (GSCBPS) is an international, peer reviewed, open access journal devoted to rapid, easy and high quality publication. GSCBPS aims to establish itself as a platform for exchanging ideas in new emerging trends in biological as well as pharmaceutical sciences that needs more focus and exposure and is always committed to publish articles that will strengthen the knowledge of upcoming Academician, Researchers and Scientists. GSCBPS is committed to provide the authors a timely and peer reviewed process for evaluation of their manuscripts. GSCBPS is intended to be abstracted and indexed in various International and National databases

GSCBPS is a monthly, international, open access, journal dedicated to various disciplines of biological, pharmaceutical and allied sciences. GSCBPS is an international medium of interaction between scientist, academicians and industrial personnel's. GSCBPS publishes manuscripts (full length research articles, review articles, mini reviews, short communications, case reports, editorials and letters to editor) on original work, either experimental or theoretical.

Topics suitable for publication in GSCBPS include, but are not limited to

Biological Science: Agricultural science, Biomaterials and Bioactive polymers, Biochemistry, Biotechnology, Bioinformatics, Botany, Cell biology, Developmental biology, Environmental biology, Forestry, Genetics, Genetic engineering, Microbiology, Molecular and structural biology, Nanobioscinece, Plant physiology and pathology, Zoology, Bioallied sciences etc.

Pharmaceutical Science : Pharmaceutics and Biopharmaceutics, Novel and Targeted Drug Delivery, Nanotechnology and Nanomedicine, Pharmaceutical Chemistry, Pharmacognosy and Ethanobotany, Phytochemistry, Pharmacology and Toxicology, Pharmacogenomics, Pharmacovigilance, Natural Product Research, Drug Regulatory Affairs, Case Study and Full clinical trials etc.

It is also our great pleasure to welcome the members of the extensive Editorial Board of GSCBPS. Launching this new journal would not have been possible without the great and much appreciated contributions from the Editorial Board members and Reviewers. We are sure that their international reputation and great expertise in the field will have a significant contribution in shaping up the journal and making GSCBPS a prestigious international journal. We hope they will continue to help us in the future.

In this inaugural issue of GSC Biological and Pharmaceutical Sciences (GSCBPS), we have total five articles from different countries reflecting the international coverage of the journal. One of the most encouraging thing for us is we

\footnotetext{
${ }^{*}$ Corresponding author

E-mail address: editor-gscbps@gsconlinepress.com
}

Copyright (C) 2017 Author(s) retain the copyright of this article. This article is published under the terms of the Creative Commons Attribution Liscense 4.0. 
received diverse yet high-quality papers across the globe. We would like to, therefore, thank our all contributing authors.

Finally, the Editors-in-chief wish to thank the authors who submitted papers to the first issue of GSCBPS. We are appreciative that they responded to our request. We are also thankful to the members of the Editorial Board who reviewed manuscript submitted to the first issue of the journal by contributing their precious feedback and advice. This inaugural issue contains five scientific articles which is very informative.

We hope that the new international journal, GSC Biological and Pharmaceutical Sciences will serve the research community well and this journal will be the most important medium of presenting ideas and research work in the relevant field. Any recommendation on how to enhance our activity in order to communicate a better journal to the authors, readers and subscribers of this journal will be always very much admired.

Thanks and regards,

\section{Dr. Chaudhari G. M.}

Editor in Chief

GSC Biological and Pharmaceutical Sciences (GSCBPS)

editor-gscbps@gsconlinepress.com 